\title{
Performance Analysis of a Domestic Refrigerator Using Various Alternative Reffrigerant
}

\author{
Sarthak. M Thakar ${ }^{1}$, R.P.Prajapati ${ }^{2}$, D.C.Solanki ${ }^{3}$ \\ ${ }^{1}$ Me. Iv Semester, Thermal Engineering, Salitar, Ahmadabad \\ ${ }^{2}$ Assistance Professor, Thermal Engineering, Salitar, Ahmadabad \\ ${ }^{3}$ Professor, Thermal Engineering, Salitar, Ahemadabad
}

\begin{abstract}
This work presents the development process of Refrigerator test ring and then carry-out the performance analysis of domestic refrigerator. The experiment platform which is called refrigerator test ring will be developed from refrigerator model. Performance of refrigerator also depends on inlet and outlet condition of each components. So in this research work refrigerator test ring will be developed and obtain performance of domestic refrigerator in term of Refrigeration Capacity, Compressor Work and Coefficient of Performance (COP) by determining two important parameter during operating condition which are temperature and pressure. So carry out this project I use different alternative refrigerant and find the data and compare the data to each other and then find the alternate of $R 134 a$
\end{abstract}

What is Refrigeration?

\section{Introduction}

Refrigeration is defined as the process of removing heat from a body or enclosed space so that the temperature first lowered and then maintained at level below the temperature of surrounding. The equipment used to maintain the required temperature is called refrigerating equipment.

\subsubsection{Types of Refrigeration system}

There are two types of refrigeration system

1. Vapour Compression Refrigeration system (VCRS)

2. Vapour Absorption Refrigeration system (VARS)

\subsubsection{VCRS system}

The below diagram shows the refrigeration circuit. The Main four processes are Evaporation, Compression, Condensation and Expansion.

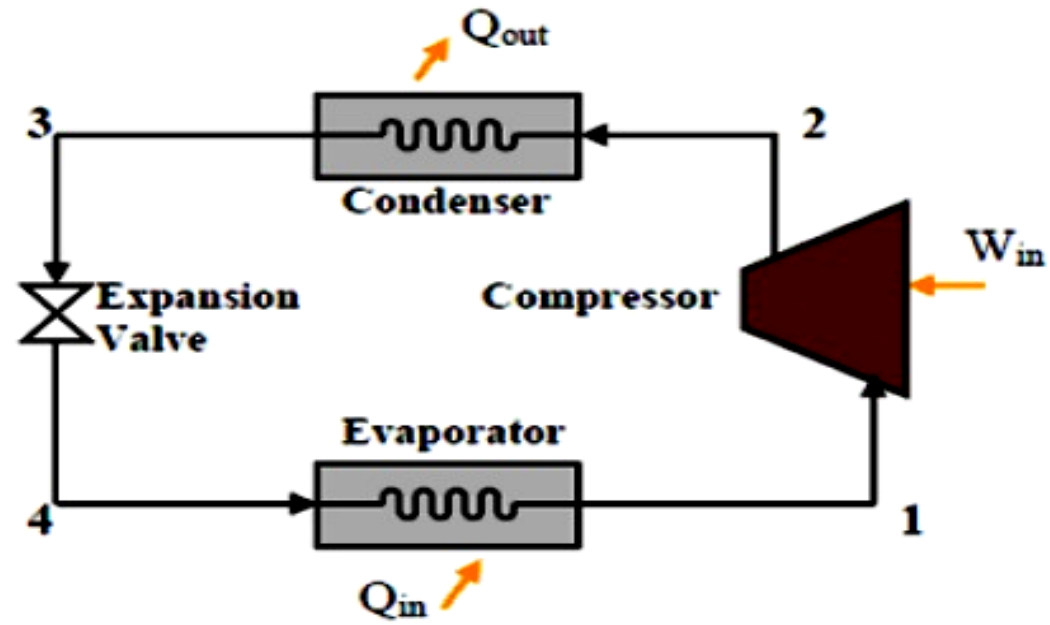

Fig. 1.1 VCRS system

The process starts with vaporization of the refrigerant in the evaporator. This is complete at point 2. Compression is used to raise the pressure of the refrigerant, point $\mathbf{3}$, so that it can condense at a higher temperature. When all the vapour has condensed, point $\mathbf{4}$, the pressure is reduced in an expansion device, and the refrigerant is returned to its original condition. 


\subsubsection{Components of Refrigeration system}

1. Compressor

2. Condenser

3. Expansion valve

4. Evaporator

\section{Compressor}

- It compresses the refrigerant. The compressor receives low pressure gas from the evaporator and converts it to high pressure gas. As the gas is compressed, the temperature rises. The hot refrigerant gas then flows to the condenser.

2. Condenser

- A condenser is a device or unit used to condense a substance from its gaseous to its liquid state, by cooling it. In so doing, the latent heat is given up by the substance, and will transfer to the condenser coolant.

3. Expansion Valve

- Its function is to meter the amount of refrigerant to be supplied to evaporator and to reduce the pressure up to evaporator pressure such that liquid can vaporise at the evaporator coil.

4. Evaporator

- An evaporator is used in an air-conditioning system to allow a compressed cooling refrigerant, to evaporate from liquid to gas while absorbing heat in the process. It can also be used to remove water or other liquids from mixtures.

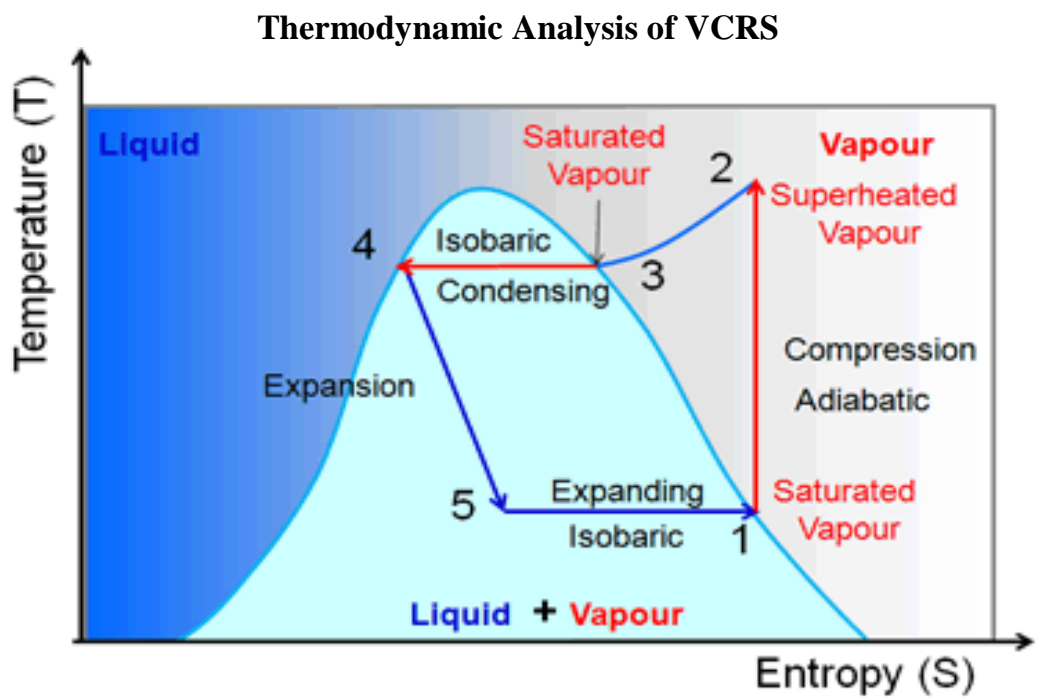

Fig. 1.2 T-S diagram of VCRS system

Process 1-2: Isentropic compression of saturated vapour in compressor

Process 2-3: Isobaric heat rejection in condenser

Process 3-4: Isenthalpic expansion of saturated liquid in expansion device

Process 4-1: Isobaric heat extraction in the evaporator

Expansion is a constant enthalpy process. It is drawn as a vertical line on the above P-h diagram. No heat is absorbed or rejected during this expansion, the liquid just passes through a valve, like water coming out of a tap. The difference is, that because the liquid is saturated at the start of expansion by the end of the process it is partly vapour. Point 1 is inside the curve and not on the curve as described in the Evaporation process. The refrigerant at the beginning of the vaporization is already partly evaporated. This depends on the shape of the curve, and the start and end pressures. The Compression process is shown as a curve. It is not a constant enthalpy process. The energy used to compress the vapour turns into heat, and increases its temperature. This tends to raise the temperature of the vapour, making point 3 move further into the superheated part of the diagram as compression progresses. Point 3 is outside the curve as described in the Compression process. This means that before Condensation can start, the vapour has to be cooled down. 


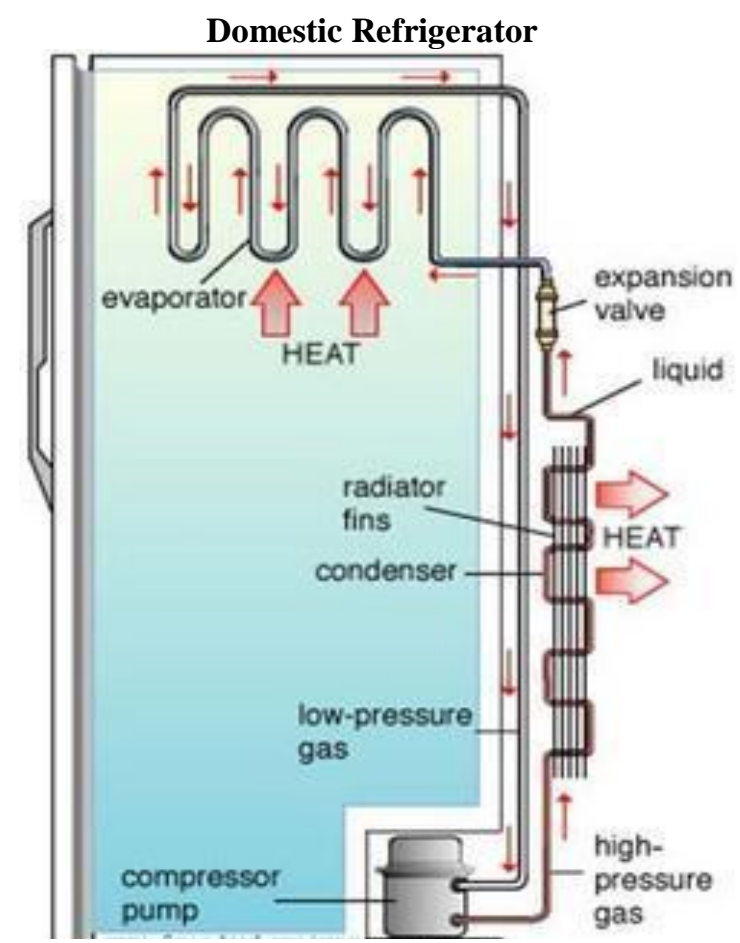

Fig. 1.4 Domestic Refrigerator

\subsubsection{Internal Parts of the Domestic Refrigerator}

The internal parts of the refrigerator are ones that carry out actual working of the refrigerator. Some of the internal parts are located at the back of the refrigerator, and some inside the main compartment of the refrigerator.

1) Refrigerant: The working substance used to make refrigeration is called the refrigerant. The refrigerant run through all the inner parts of the refrigerator. It is the refrigerant that carries out the cooling effect in the evaporator. It absorbs the heat from the body to be cooled in the evaporator (chillier or freezer) and throws it to the atmosphere via condenser. The refrigerant keeps on recalculating through all the inner parts of the refrigerator in cycle.

2) Compressor: The compressor is to be found at the rear of the refrigerator and in the bottom area. The compressor sucks the refrigerant from the evaporator and discharges it at high pressure and temperature. The compressor is driven by the electric motor and it is the major power intense devise of the refrigerator. In most of the refrigerator reciprocating and hermitically sealed compressor are used.

3) Condenser: In refrigerator air-cooled condenser is used since, the constriction of air-cooled condenser is very simple. The condenser is the thin coil of copper tubing situated at the back of the refrigerator. The refrigerant from the compressor come in the condenser where it is cooled by the atmospheric air thus losing heat absorbed by it in the evaporator and the compressor. To increase the heat transfer rate of the condenser, it is finned externally.

4) Expansion valve or the capillary: The refrigerant leave-taking the condenser enters the expansion devise, which is the capillary tube in case of the household refrigerators. The capillary is the thin copper tubing made up of number of turns of the copper coil. When the refrigerant is passed through the capillary its pressure and temperature drops down suddenly. And it is a constant enthalpy process.

5) Evaporator or freezer: The refrigerant at very low pressure and temperature enters the evaporator or the freezer. The evaporator is the heat exchanger made up of several turns of copper or aluminium tubing. In domestic refrigerators the plate types of evaporator is used as shown in the figure above. The refrigerant absorbs the heat from the substance to be cooled in the evaporator, gets evaporated and it then sucked by the compressor. This cycle keeps on repeating.

6) Temperature control devise or thermostat: To control the temperature inside the refrigerator there is thermostat, whose sensor is connected to the evaporator. The thermostat setting can be done by the round knob inside the refrigerator compartment. When the set temperature is reached inside the refrigerator the thermostat stops the electric supply to the compressor and compressor stops and when the temperature falls below certain level it restarts the supply to the compressor.

7) Defrost system: The defrost system of the refrigerator helps removing the excess ice from the surface of the evaporator. The defrost system can be operated manually by the thermostat button or there is automatic 
system comprising of the electric heater and the timer.

\section{Experiment set up, Methodology: Refrigerator Model Details}

\begin{tabular}{|l|l|}
\hline Brand & Whirlpool \\
\hline Model name/year & DC -5256/2012 \\
\hline Freezer Capacity ( liter ) & 80 \\
\hline Fresh Food Compartment Capacity (liter) & 230 \\
\hline Power Rating & $160 \mathrm{~W}$ \\
\hline Current Rating & $0.9 \mathrm{~A}$ \\
\hline Voltage & $220-240 \mathrm{~V}$ \\
\hline Frequency & $50 \mathrm{~Hz}$ \\
\hline No of door & Single \\
\hline Compressor & Hermetic - sealed \\
\hline Refrigerant type & R134a \\
\hline
\end{tabular}

Table4.1 specification refrigerator

This Section provides the information about the how I was developed the experiment set up and how I will carry out the test procedure the during experiment. First the experiment test ring developed from the refrigerator model. To perform the experiment and develop the test ring 230L refrigerator is selected. and Fig. shows the line diagram of test ring and connection point of pressure and temperature measurement. Now from the experiment test ring there 6 point of temperature measurement and 2 point of pressure measurement. Two point of pressure measurement one of the one point in suction side and another point is in discharge line. The pressure gauge are used for the pressure measurement so compound gauge is fitted on discharge line due to high pressure and vacuum gauge is fitted on suction line due to low pressure as shown in the fig. Now there five pointis is temperature measurement so one the point of temperature measurement is in evaporator means in the freezer compartment of refrigerator. One point is for the measurement of food storage cabinet. And point is located on the compressor inlet, compressor outlet, condenser inlet and condenser outlet. So now for the temperature measurement digital thermometer are used. Ammeter is also used for the current measurement. So this the procedure of the experiment set up

Now for the test procedure the evacuation and vacuuming is done by the another compressor. And vacuum is done up to the $25 \mathrm{in} / \mathrm{hg}$. This is required for the cleaning of the lines by removing moisture, air and oil. Now after that the refrigerant is charged by the charging system and when the evaporator temp. set at $10^{\circ} \mathrm{c}$ and $1^{\text {st }}$ I charged the R $134 \mathrm{a}$ and collected the data like pressure and temperature every 15 minutes during the running the refrigerator and also collected the data various evaporator temperature. After collecting the data $\mathrm{R}$ $134 \mathrm{a}$ is removed and refrigerator are charged by another alternative refrigerant like R 290, R 600, R 152a and mixture of the different refrigerant and collected the data. After collecting the experimental data I found different parameter like COP, Refrigerant effect, Compressor power, Volumetric cooling capacity, mass flow rate , compressor power per ton, compression ratio etc. and then compare this data each other to the refrigerant and find the alternative refrigerant which gives the better performance in compare with R 134a.

So in this way I will be found the best alternative of R 134a

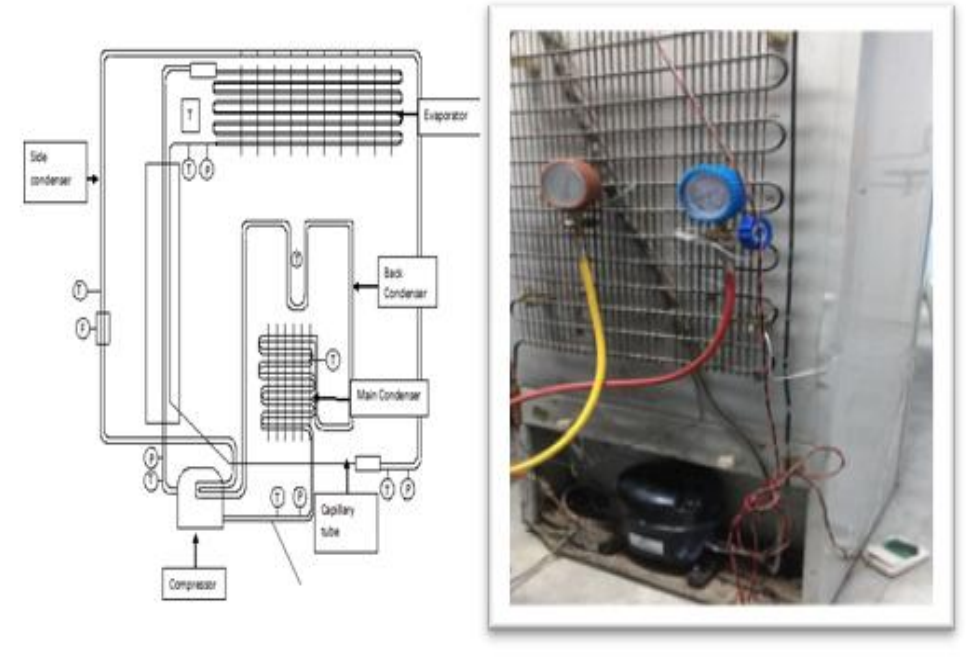




\begin{tabular}{|l|l|l|l|l|l|l|}
\hline \multicolumn{1}{|c|}{$\begin{array}{c}\text { Refrigerant } \\
\text { (category) }\end{array}$} & \multicolumn{1}{|c|}{$\begin{array}{c}\text { Chemical } \\
\text { Formula }\end{array}$} & $\begin{array}{c}\text { Normal } \\
\text { boiling point }\end{array}$ & $\begin{array}{c}\text { Critical } \\
\text { Temperat } \\
\text { ure }\left({ }^{\circ} \mathrm{C}\right)\end{array}$ & ODP & GWP & Safety group \\
\hline R 134a & $\mathrm{CF}_{3} \mathrm{CH}_{2} \mathrm{~F}$ & -26.07 & 101.6 & 0 & 1380 & $\mathrm{~A} 1$ \\
\hline R 152a & $\mathrm{CH}_{3} \mathrm{CHF}_{2}$ & -24.2 & 113.5 & 0 & 20 & $\mathrm{~A} 1$ \\
\hline R 290 & $\mathrm{C}_{3} \mathrm{H}_{8}$ & -42.1 & 96.8 & 0 & 20 & $\mathrm{~A} 3$ \\
\hline R 600 & $\mathrm{C}_{4} \mathrm{H}_{10}$ & -0.56 & 153 & 0 & 20 & $\mathrm{~A} 3$ \\
\hline R 600a & $\left(\mathrm{CH}_{3}\right)_{3} \mathrm{CH}$ & -11.67 & 135 & 0 & 20 & $\mathrm{~A} 3$ \\
\hline R600/290(50/50) & $\mathrm{C}_{4} \mathrm{H}_{10}+\mathrm{C}_{3} \mathrm{H}_{8}$ & -21.33 & 124.9 & 0 & 20 & $\mathrm{~A} 3$ \\
\hline R134a/R290(50/50) & $\mathrm{CF}_{3} \mathrm{CH}_{2} \mathrm{~F}+\mathrm{C}_{3} \mathrm{H}_{8}$ & -34.07 & 99.2 & 0 & 20 & $\mathrm{~A} 3$ \\
\hline R 436a & & -51.6 & 78.1 & 0 & 600 & $\mathrm{~A} 3$ \\
\hline R134a/R600(50/50) & $\mathrm{CF}_{3} \mathrm{CH}_{2} \mathrm{~F}+\mathrm{C}_{4} \mathrm{H}_{10}$ & -13.31 & 133.25 & 0 & 20 & $\mathrm{~A} 3$ \\
\hline
\end{tabular}

Table 1.1 Refrigerant Property

\section{Calculation}

1. Compressor Work done $(\mathrm{w})=(\mathrm{h} 2-\mathrm{h} 1) \mathrm{KJ} / \mathrm{Kg}$

2. Refrigerant effect Per Kg $(\mathrm{RE})=(\mathrm{h} 1-\mathrm{h} 3) \mathrm{KJ} / \mathrm{Kg}$

Where, $\mathrm{h}_{1}=$ Specific Enthalpy at the inlet of compressor $(\mathrm{KJ} / \mathrm{Kg})$

$\mathrm{h}_{2}=$ Specific Enthalpy at the outlet of compressor $(\mathrm{KJ} / \mathrm{Kg})$

$\mathrm{h}_{3}=$ Specific Enthalpy at the outlet of condenser $(\mathrm{KJ} / \mathrm{Kg})$

$\mathrm{h}_{4}=$ Specific Enthalpy at the inlet of evaporator $(\mathrm{KJ} / \mathrm{Kg})$

3. COP $=\frac{\text { Refrigerant effect }}{\text { Compressor work done }}$

4. Mass flow rate $=\frac{3.517}{\mathrm{RE}}$

5. Compression ratio $=\frac{\text { Discharge pressure }}{\text { Suction pressure }}$

6. Compressor power per ton $=$ Mass flow rate $\times$ Compressor work done

7. Volumetric refrigerant efficincy $=\frac{\mathrm{RE}}{\mathrm{Vg}_{1}}=\frac{113.34}{0.04944}=2942.15 \mathrm{~kg} / \mathrm{m}^{3}$

Notes:- Values of $h_{1}, h_{2}, h_{3}, h_{4}$ are calculated by using pressure enthalpy diagram related to the various alternative refrigerant during calculation.

III. Result And Discussion

In this chapter I discuss the and carry out the comparison of the various refrigerant which I use in my project work and after I go for result and find best alternative refrigerant of R 134a

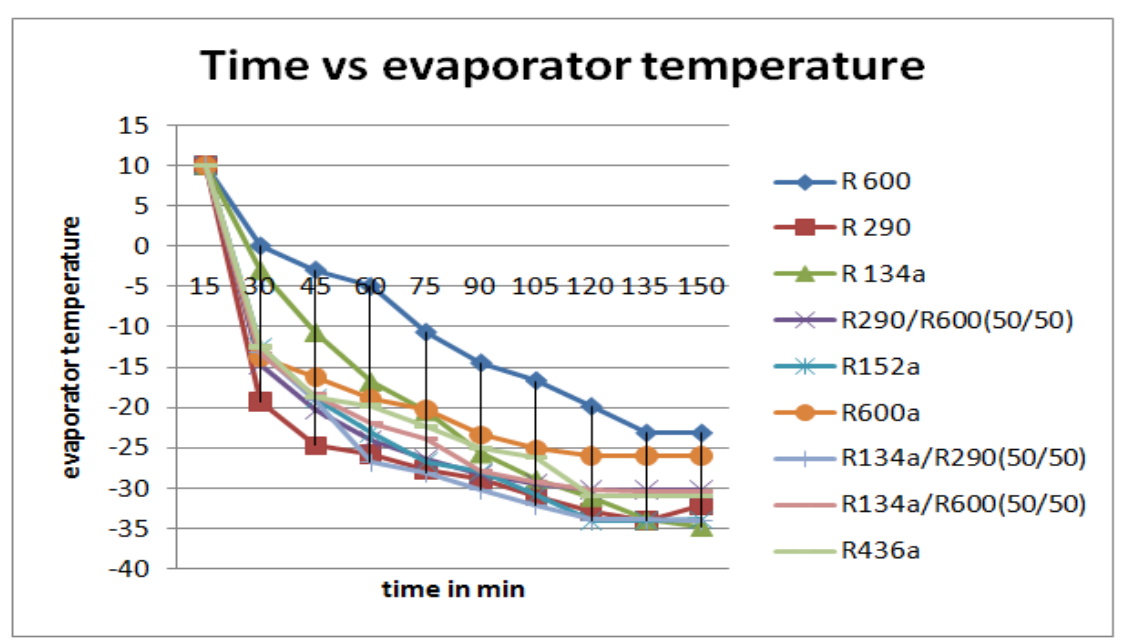

Fig 6.1 Time VS evaporator temperature 
As shown in the fig. at the staring of refrigerator the evaporating temp. of all refrigerant is set to $10^{\circ} \mathrm{c}$ and as the refrigerator run the evaporator temp. is decrease and after some time it achieve to constant temp. During the starting of 15 minute evaporator temp. drop is high for all refrigerant and among the refrigerants R290 has high temp. drop and R 134a has low temp. drop. As shown in the fig R132a and R152A has achieved highest evaporating temp. after $150 \mathrm{~min}$. and R 600 and R600a has a low evaporating temp.

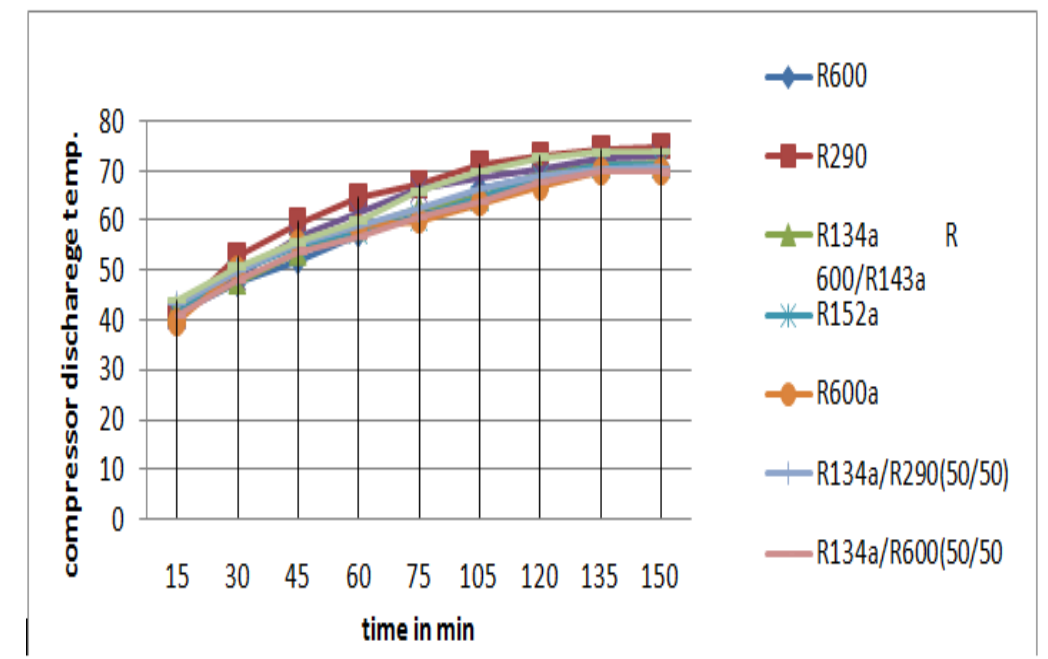

As shown in the fig5.2 the discharge temp. as the staring of refrigerator islow and than increase as the refrigerator and as the time pass the increase rate in discharge temp. is low and after some time it achieve constant temperature. So amoung the Refrigerant R290 has a highest discharge temp. while R 600 has a lowest discharge temp.

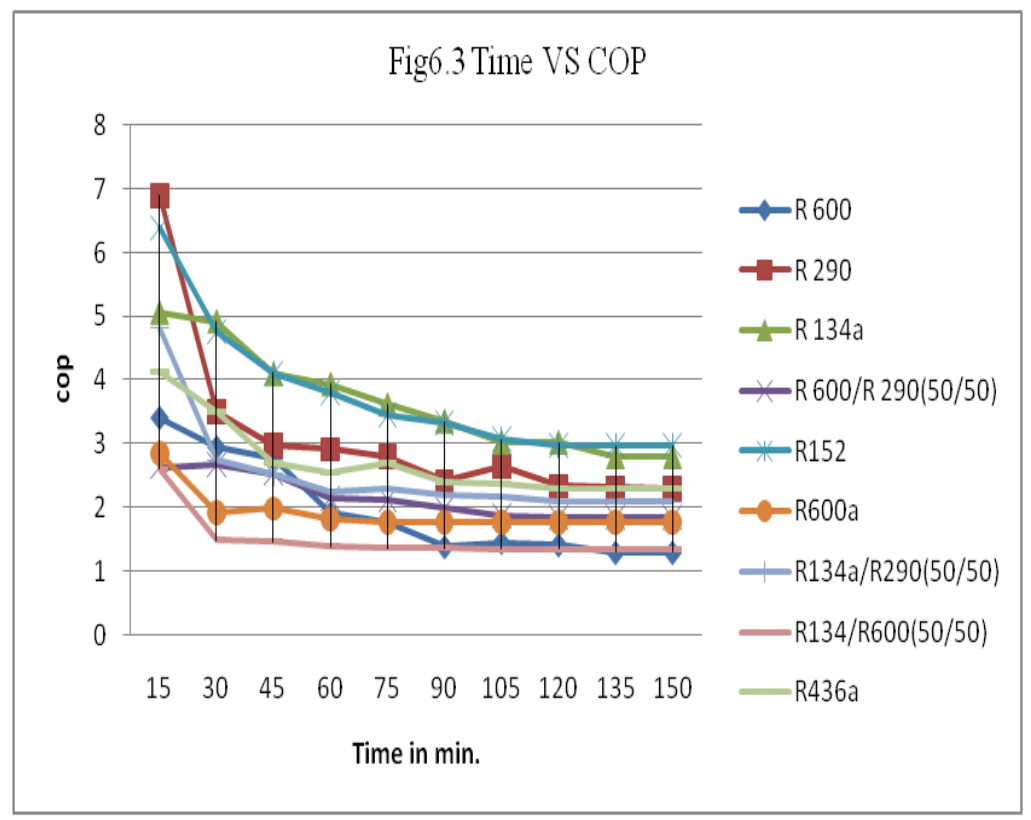

As shown in fig 5.3 the cop at staring of refrigerator is high and R 290 and R152a has a high COP as the starting and as the time goes the cop all refrigerant is start decreasing and reach the constant value. So from the fig is the clear that the COP of R 152a has a high value than another refrigerant and COP of R 290 and R 436a is also near to the COP of R 134a. And the refrigerant R 600 has low COP compare with another refrigerant blend of R 134/R 600an has low COP. Bt from fig. its also say that the R 152 and R 290 give the better performance than another alternate refrigerant. So its possible that the R 152a and R 290 has a better alternate refrigerant. 


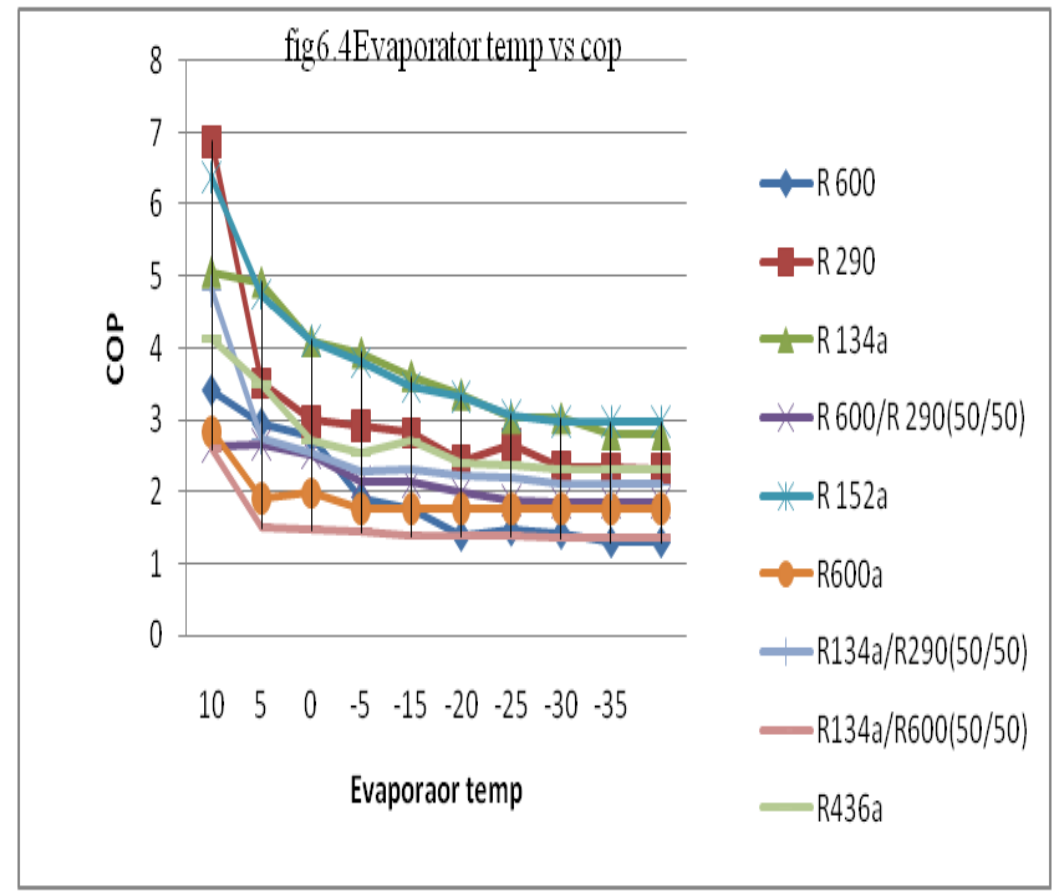

As Shown in fig 5.4 COP decrease as the evaporator temp. is decreasing and R 152a has a high COP at low evaporating temp. and the blend of R 600/134 and R 600 has low COP at low evaporating temp.

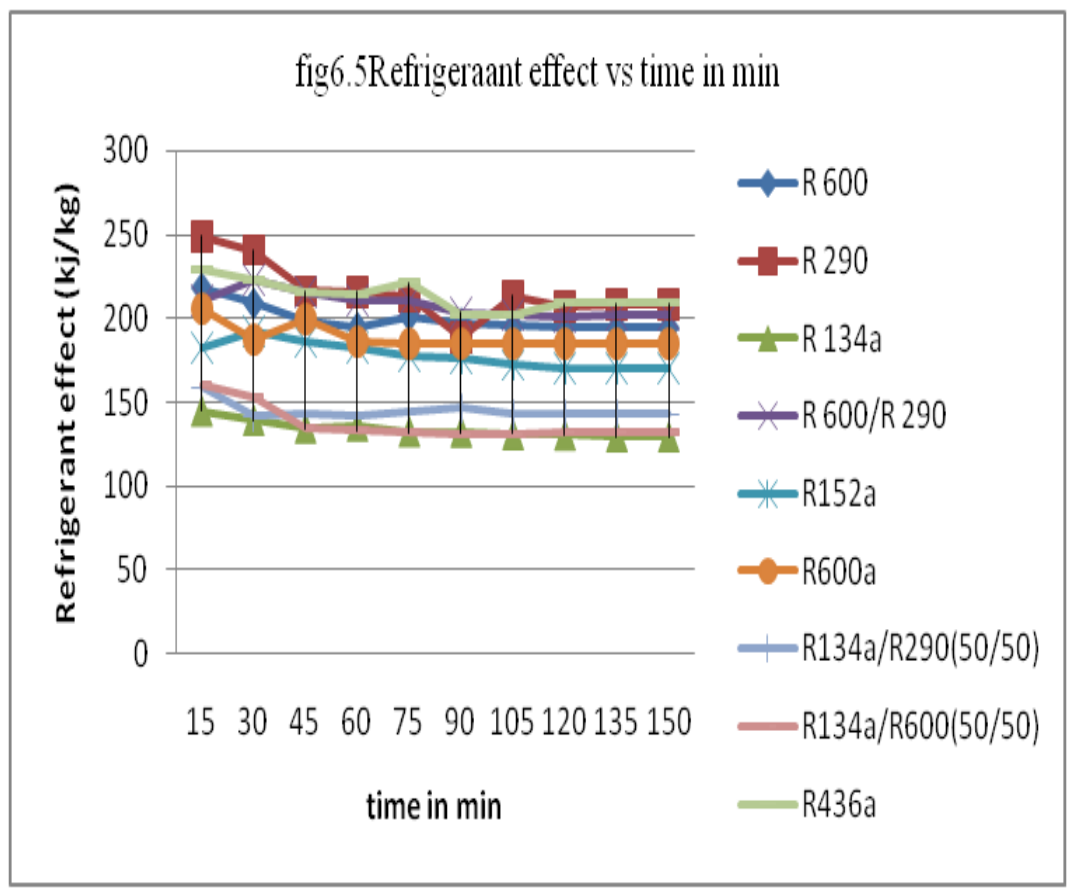

As shown in the fig at staring of the time the refrigerant is high and than it is start deceasing as the time pass away and one time refrigerant effect is become constant it is due to the setting temp. difference in the cabinet . Now from fig is clear that the refrigerant effect of R 290 has high value than any another refrigerant . But at a same time the refrigerant effect is low for R 134a refrigerant. And from the fig it is also clear that the after some time refrigerant effect has a constant value. 


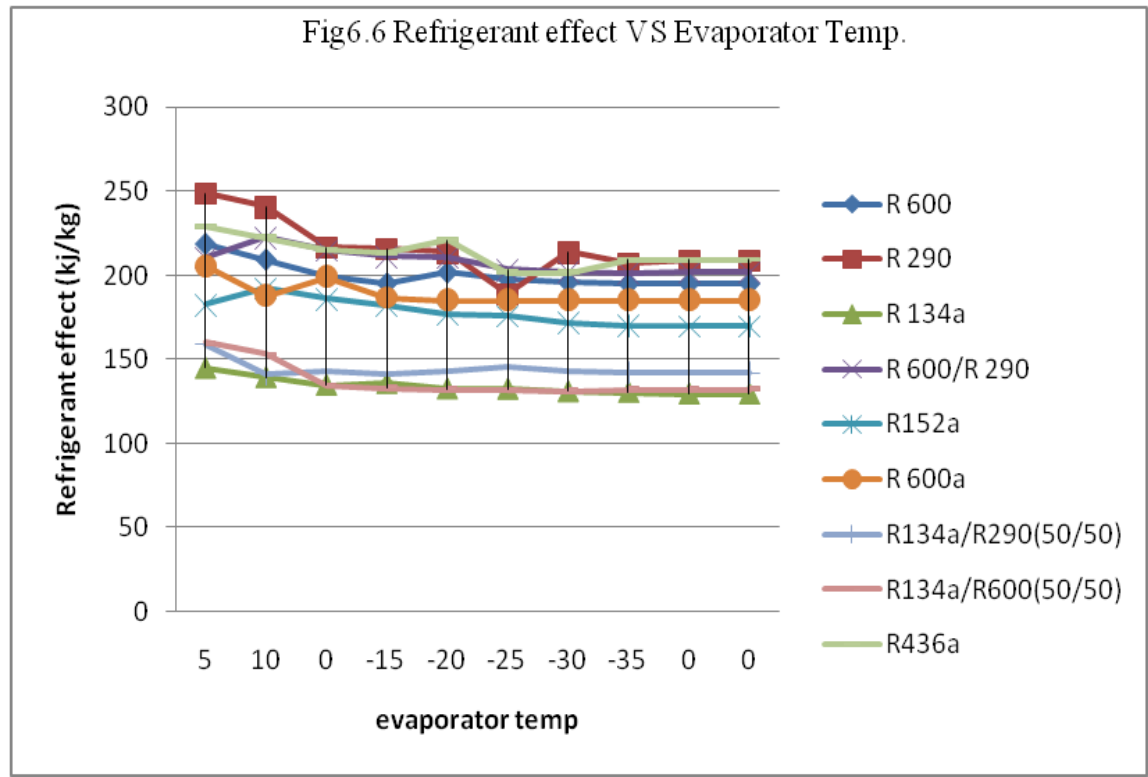

Now from above fig it also clear that the with increasing the evaporator temp. the net refrigerant effect also decrease and achieve the constant value. Refrigerant R 152a and R 134a around the $-35^{\circ} \mathrm{c}$ evaporating temp. low refrigerant effect and also achieve the constant value. While as a same temp. refrigerant R 290 and R 436a high refrigerant effect among the refrigerant

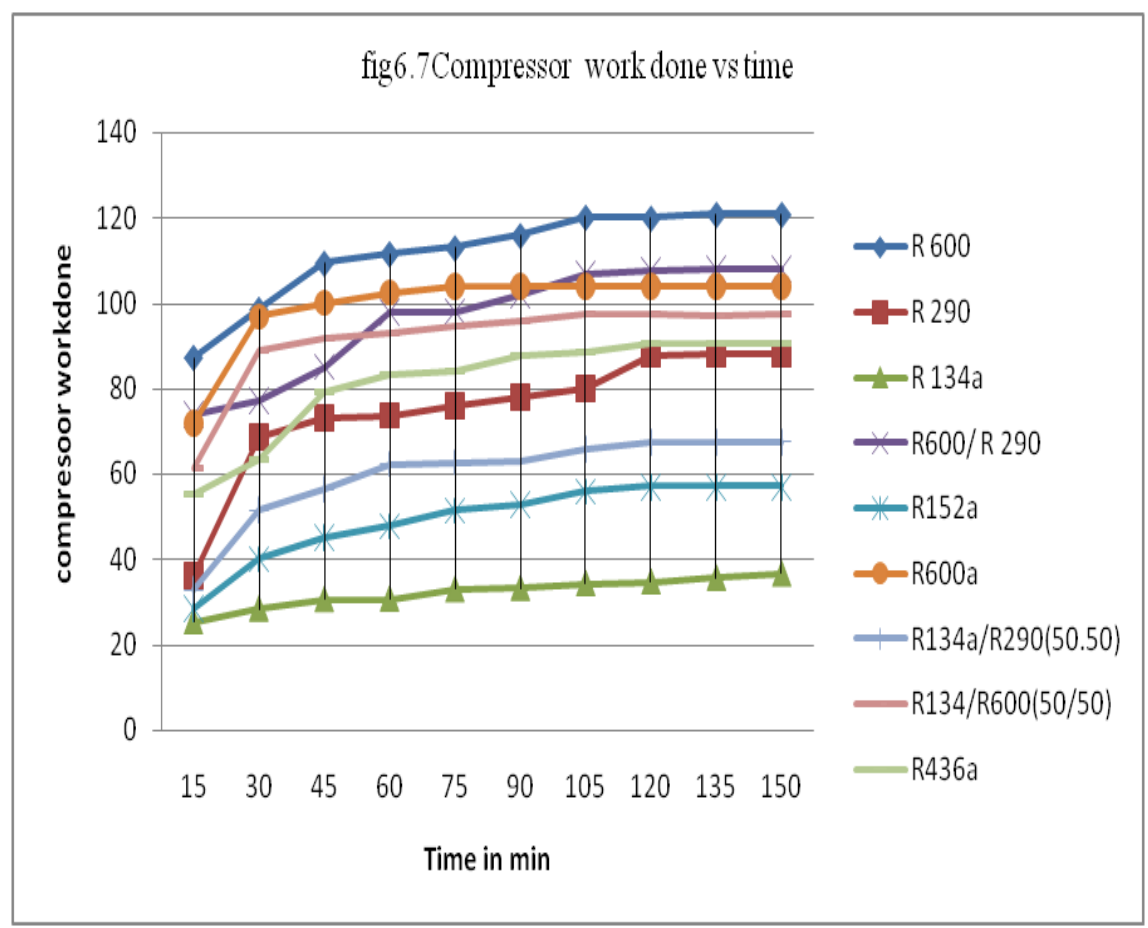

As shown in fig at the staring of the time the compressor work done is low but as the time increase the compressor work done also increase and after some time it become a constant. The rate of increasing the compressor work done is most of the same for all of the refrigerant. From fig it I clear that the compressor work done is low for R 134a and R 152a than another refrigerants . while the work done by the R 290 and R 436a Refrigerant is quite high than R 134a .Now compressor work for refrigerant R 600 is high and also work done for refrigerant $\mathrm{R} 600 \mathrm{a}$ is high than another refrigerant 


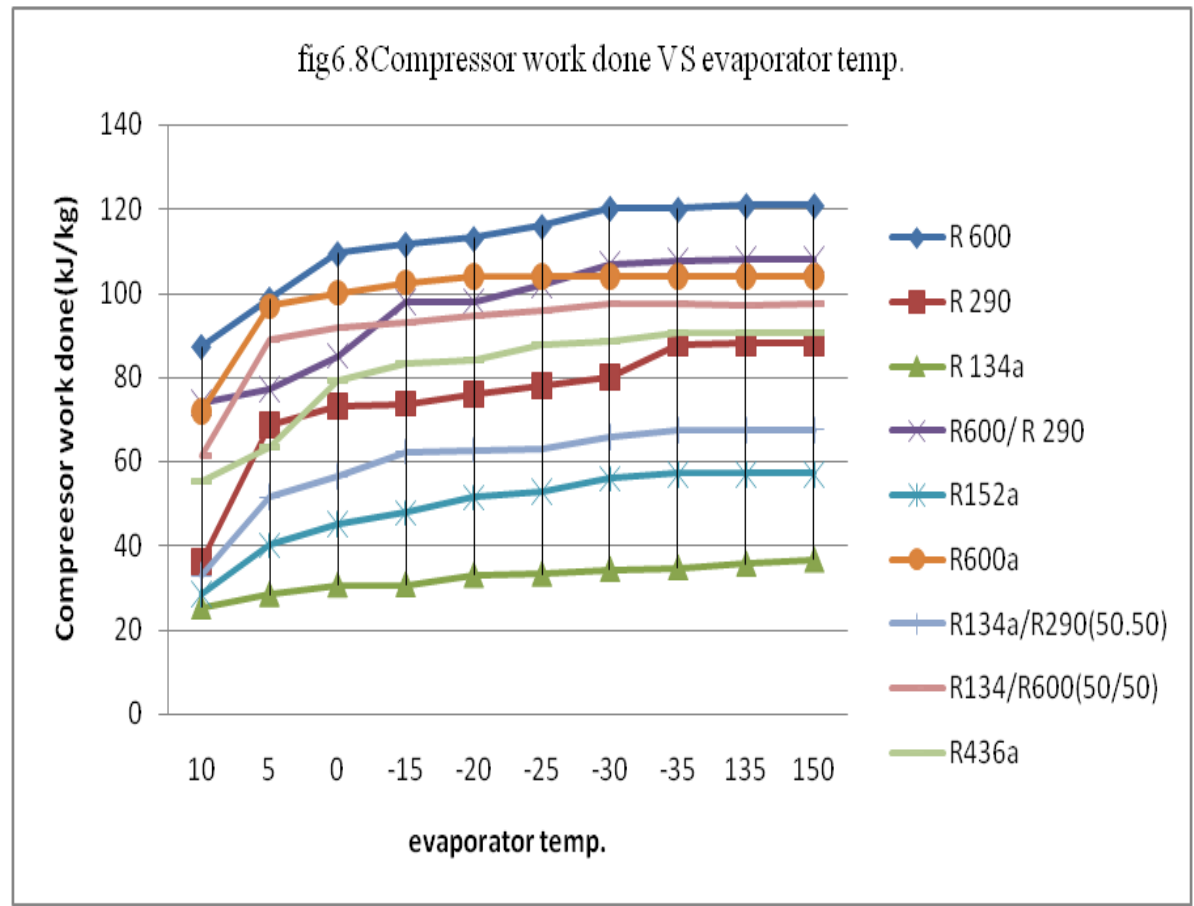

As shown in fig it is clear that the Compressor work increasing as the evaporation temp increase. For R 134a at $-35^{\circ}$ the compressor work is low than another refrigerant bt work done by the R 152a is near the work done of $\mathrm{R}$ 134a. And as the same evaporator temp. work done for R 600 and R 600a is high than another refrigerant

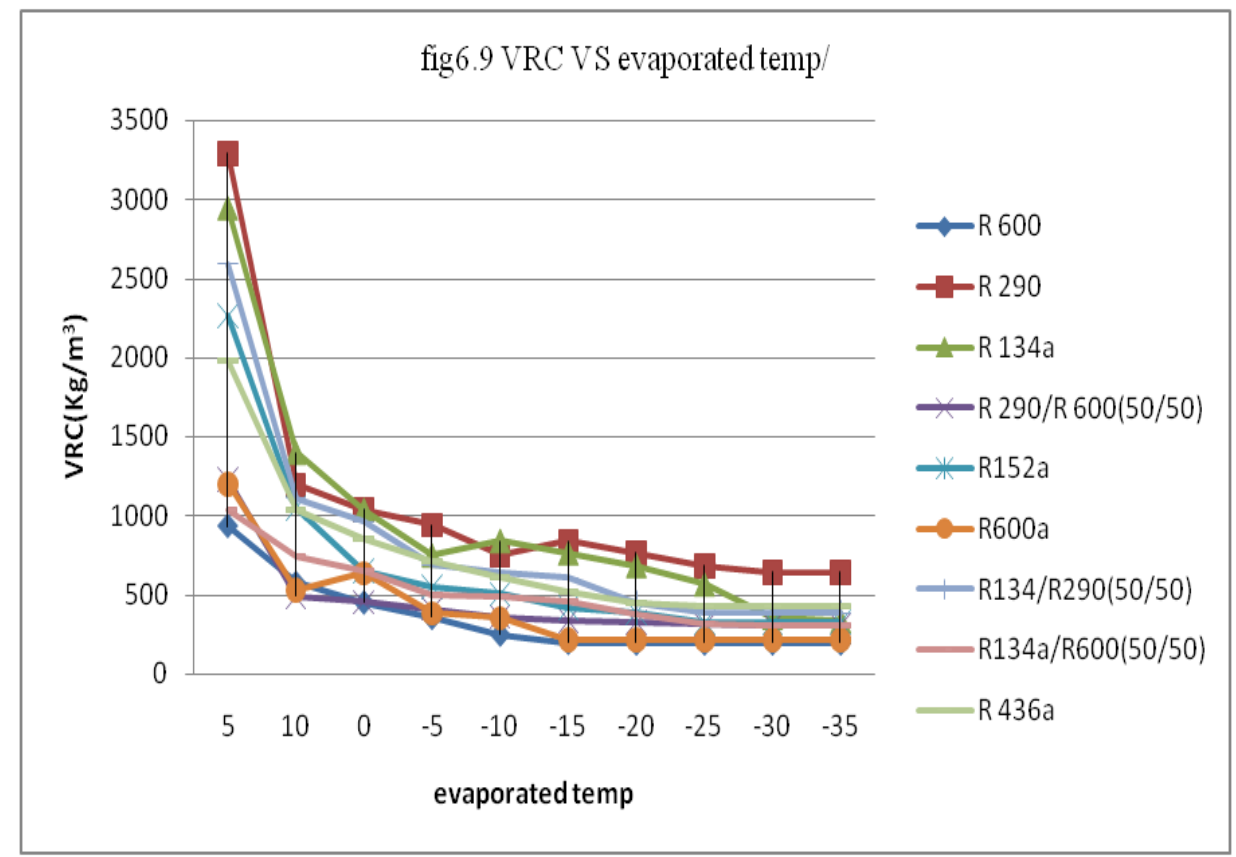

Now fig 5.10 its shows the variation of volumetric refrigerant capacity to the evaporator temp. from fig.it is clear that the VRC decrease as the evaporated temp. decrease so it is clear that the R 290 has high volumetric refrigerant capacity and R $134 \mathrm{a}$ and $\mathrm{R} 152$ a has a slightly low volumetric refrigerant capacity as compared to the R290 refrigerant. While as same temp. refrigerant R 600 and R 600a has low volumetric refrigerant capacity than another refrigerant. 


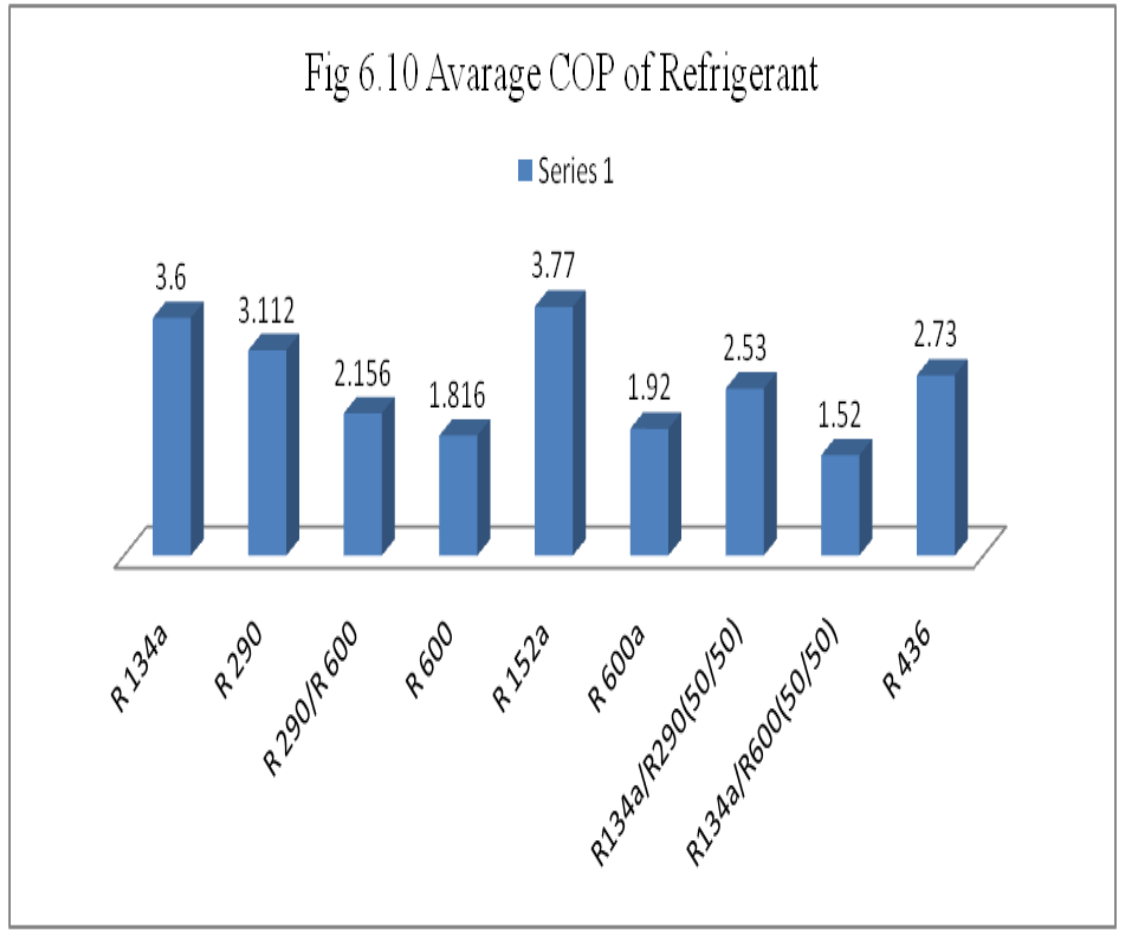

Fig. shows the avg. COP of all refrigerant.

So from fig. it is clear that the avg. COP of the R 152a is high than another refrigerant and also high than R 134a and also avg. COP of R 290 is near the R 134a. while avg. COP of mixture of R 134 and R 600 is very low. Avg. COP of R 153a is 3.8 and R 134a 3.6 and lowest COP is 1.50 of mixture of R 134a and R 600

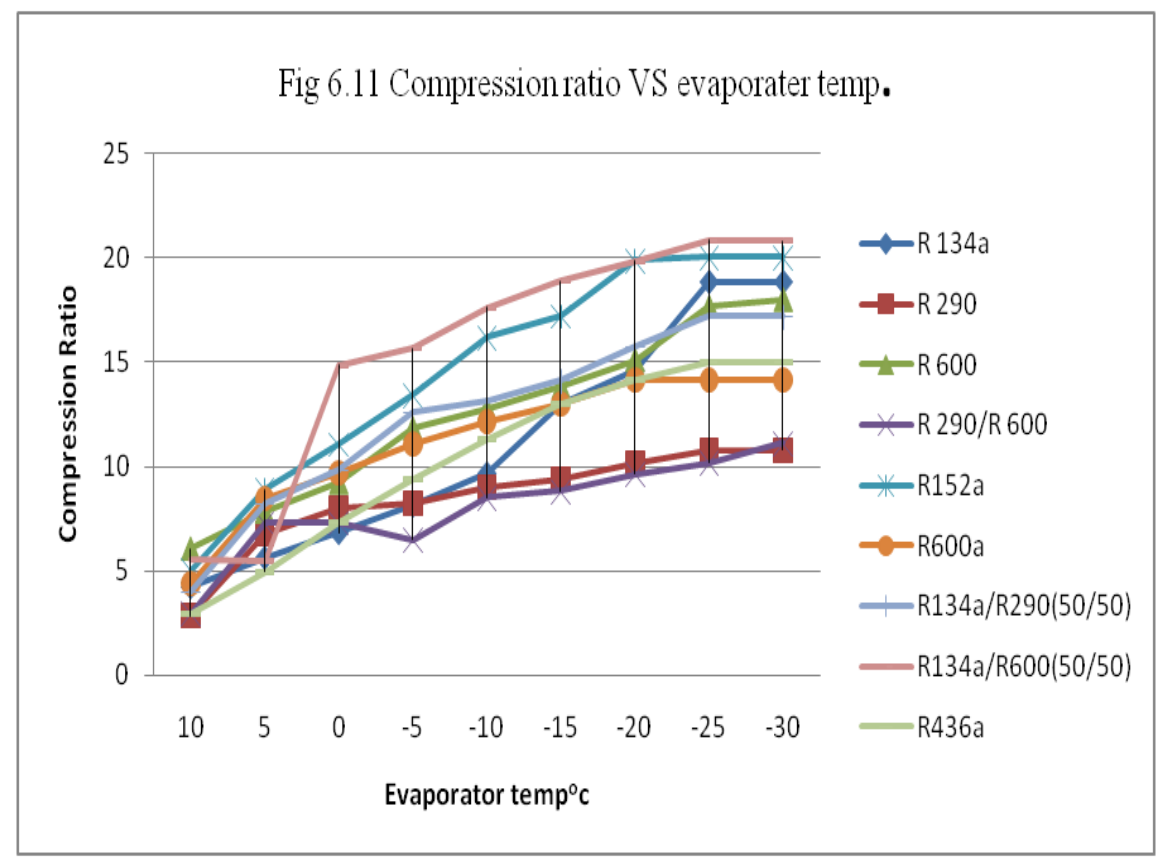

As shown in the fig the compression ratio increase with decrease the evaporator temp. From fig, it is clear that the mixture of R 134a and R 600 and R 600 has high compression ratio and R 134a and R152a has same compression ratio while the Refrigerant R 290 and mixture of R 134a and R 290 has low compression ratio as same temp than any other refrigerant. 


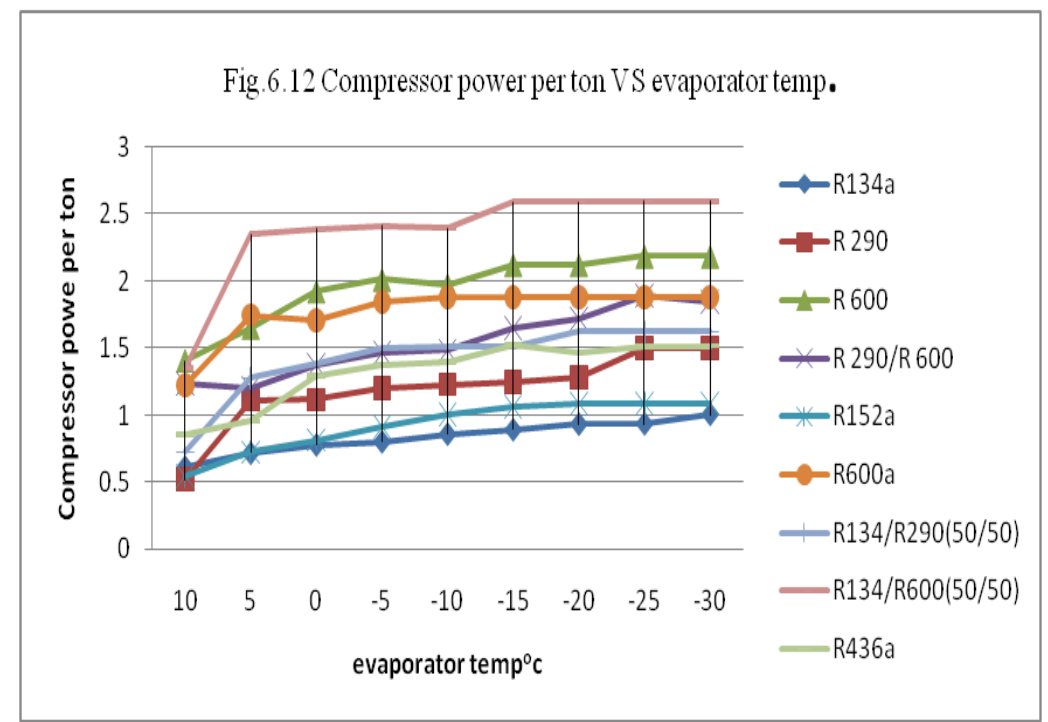

As shown in the fig Compressor power per ton is increase as the temp. of evaporator increase. Compressor power per ton is high for the mixture of R134a and R600 and refrigerant R 600. While compressor power per ton is low for $\mathrm{R} 134 \mathrm{a}$ refrigerant and at $-30^{\circ} \mathrm{c}$ temp. compressor power is same for refrigerant $\mathrm{R} 152 \mathrm{a}$ and R $134 \mathrm{a}$

IV. Conclusion And Results

In this study performance analysis of the domestic refrigerator carried out by using various alternative refrigerants and blending of refrigerant in order to find the alternate of $\mathrm{R} 134 \mathrm{a}$.

Based On The Investigation Results, The Following Conclusion Drawn:

1. Out all the refrigerants R290, R600a, R600 and R152a has the best desirable environment properties, it has zero Ozone Depletion Potential(ODP) and low global warming potential(GWP)

2. The COP of the R 152a Refrigerant is $17 \%$ is high than the R 134a and COP of R 290 is only $18 \%$ less than $R$ 134a. During the evaporator temp. range of $-25^{\circ} \mathrm{c}$ to $-30^{\circ} \mathrm{c}$ R 152a has a high COP than another refrigerant while mixture of R 134a and R 600 and R 600 has low COP in compare with another refrigerant.

3. Discharge temp. of R 290 is highest in compare with another refrigerant and R 436a has slightly low discharge temp. than R290. R 134a and R 152a has same discharge temp. and R 600 and R 600 has low discharge temp. among the refrigerants.

4. Among the all refrigerants R290 has high refrigerant effect and is net refrigerant effect is $215.98 \mathrm{KJ} / \mathrm{Kg}$. And the refrigerant R 134a and R 152a has nearly same amount of refrigerant effect.

5. During the evaporator temp. rang of $-20^{\circ} \mathrm{c}$ to $-30^{\circ} \mathrm{c} \mathrm{R} 152 \mathrm{a}$ has high compression ratio around the 20.22 while the R 134 has nearly same to the R 152a and its pressure ratio is 18.18 and Refrigerant R 600 and R 600a also compression ratio near the R 152a. While the R 290 and mixture of R 290 and R 600 has low compression ratio near the 11.11 .

6. During the evaporator temp. rang of $-20^{\circ} \mathrm{c}$ to $-30^{\circ} \mathrm{c}$ the work done by the compressor is low for the $\mathrm{R} 134 \mathrm{a}$ around the 39.13 and the work done by the R 152a is slightly higher around the 17\%.and for the R290 is 27 \% higher than the R134a. And for the refrigerant R 600 and R 600a compressor work done is higher among the all refrigerant.

7. Now power consumption is low for R 152a and $18 \%$ lower than the R 134a. power consumption for R 290 and R 436a is also high than R 134a and R 152a. Bt the refrigerant R 600a and R 600 and mixing of R134a and $\mathrm{R} 600$ the power consumption is more high than the R 134a.

8. Volumetric cooling capacity For R 290 is high and is higher than R 134a is $12.2 \%$. Volumetric cooling capacity is same for R 134a and R 152a. But Volumetric cooling capacity is much lower for the R 600 and $\mathrm{R} 600 \mathrm{a}$ around the $352.45 \mathrm{Kg} / \mathrm{m}^{3}$.

9. In this study I used the mixture of R134/R600(50/50), R290/R600(50/50) and R134a/R290(50/50).But this mixture has undesirable characterises such has a low COP, high power consumption, high compression ration and low volumetric cooling capacity. But from these three mixture the mixture of $\mathrm{R} 134 \mathrm{a} / \mathrm{R} 290(50 / 50)$ is give better performance but this two refrigerant are not properly mix each other.

10. R436a refrigerant also give some better performance such as its COP is very low than the R 134a so in some cases it also use as the alternate of $\mathrm{R} 134 \mathrm{a}$. 
But R152a and R290 refrigerants has approximately same performance with the R134a. So R152a and R290 has good alternate of R134a refrigerant.

\section{References}

[1]. Performance comparison of vapour-compression refrigeration system using various alternative refrigerants A.S. Dalkilic, S. Wongwises

[2]. The study and performance of a modified conventional refrigerator to serve as a PV powered one Socrates Kaplanis, Nikolaos Papanastasiou

[3]. Performance of a domestic refrigerator under influence of varied expansion device capacity, refrigerant charge and ambient temperature Erik Bjork, Bjorn Palm

[4]. Theoretical analysis of a vapour compression refrigeration system with R502, R404A and 507A Akhilesh Arora, S.C. Kaushik

[5]. A review on exergy analysis of vapour compression refrigeration system J.U. Ahamed, R. Saidur, H.H. Masjuki

[6]. Vapour Compression Refrigeration Systems, nptel IIT Kharagpur

[7]. Khorshid E., Alshiraan B., Alsairafi A., Alzemi A., Allahddad A., 2011,

[8]. "Performance investigation on new refrigerant mixture"pp15-20.

[9]. Rasti M., Hatamipour M.S., Aghmiri S.F., Tavakoli M., 2012, "Enhancement of domestic refrigerator"s energy efficiency index using a hydrocarbon mixture refrigerant," Measurement 45 pp:1807-1813.

[10]. Sattar M. A., Saidur R., Masjuki H. H., 2007 "Performance investigation of domestic refrigerator using pure hydrocarbons and blends of hydrocarbons as refrigerants," World Academy of Science, Engineering and Technology 29 pp:223-228.

[11]. Saidur R., Kazi S.N., Hossain M.S., Rahman M.M., Mohammed H.A.

[12]. 2011, "A review on the performance of nano particles suspended with refrigerants and lubricating oils in refrigeration systems," Renewable and Sustainable Energy Reviews 15,pp: 310-323.

[13]. Corberan J. M., Segurado J., Colbourne D., Gonzalvez J., 2008, "Review of standards for the use of hydrocarbon refrigerants in $\mathrm{A} / \mathrm{C}$, heat pump and refrigeration equipment," International Journal of Refrigeration 31, pp:

[14]. 748-756.

[15]. Cengel Y. A., Bole M. A., Thermodynamics, An Engineering Approach 7e. pp:610-611.

[16]. Chen S., Judge J. F., Groll E. A., Radermacher R., 1994, "Theoretical Analysis of Hydrocarbon Refrigerant Mixtures as a Replacement for HCFC -22 for Residential Uses", International Refrigeration and Air Conditioning Conference, pp: 225-230.

[17]. Kim M. H., Lim B. H., Chu E. S., 8 Oct 1998, "The Performance Analysis of a Hydrocarbon Refrigerant R-600a in a Household Refrigerator/Freezer", KSME International Journal, Vol. 12, No. 4, pp.753 760.

[18]. Liu Z., Haider I., Liu B. Y., Radermacher R., 1994, "Test Results of Hydrocarbon Mixtures in Domestic Refrigerator/Freezers", Center for Environmental Energy Engineering (CEEE) University of Maryland College Park, Maryland, USA, PP: 22-31.

[19]. Maclaine-cross I. L., Leonardi E., June 1997, "Why Hydrocarbons Save Energy", School of Mechanical and Manufacturing Engineering The University of New South Wales Sydney NSW, Australia 2052, Published in AIRAH Journal, Volume 51 No. 6, pp. 33-37.

[20]. Baskaran A., Mathews P. K., September 2012, "A Performance Comparison of Vapour Compression Refrigeration System Using Eco Friendly Refrigerants of Low Global Warming Potential”, International Journal of Scientific and Research Publications, Volume 2, Issue 9, ISSN2250-3153, pp: 1-8.

[21]. Almeida I. M. G., Barbosa C. R. F., Fontes F. A. O., December 2010, "THERMODYNAMIC AND Thermophysical Assessment Of Hydrocarbons Application In Househould Refrigerator", Engenharia Térmica (Thermal Engineering), Vol. 9, N O 01 E 02, Pp. 19-27, 